\title{
Effect of Maltose Concentration on Plant Regeneration of Anther Culture with Different Genotypes in Rice (Oryza sativa L.)
}

\author{
Seul Gi Park, Mohammad Ubaidillah, Kyung-Min Kim* \\ Division of Plant Biosciences, School of Applied BioSciences, College of Agriculture and Life Science, Kyungpook National Uni- \\ versity, Daegu, Korea. \\ Email: ahsia1004@naver.com,moh_ubaedellah@yahoo.com, "kkm@knu.ac.kr
}

Received September $14^{\text {th }}, 2013$; revised October $15^{\text {th }}, 2013$; accepted October $24^{\text {th }}, 2013$

Copyright (C) 2013 Seul Gi Park et al. This is an open access article distributed under the Creative Commons Attribution License, which permits unrestricted use, distribution, and reproduction in any medium, provided the original work is properly cited.

\begin{abstract}
This study describes the impact of different concentrations of maltose on plant regeneration of anther culture for five genotypes of rice (Oryza sativa). $\mathrm{N}_{6}$ medium was used for calli induction, while $\mathrm{N}_{6}$ medium supplemented with different concentrations of maltose, $2.0 \mathrm{mg} / \mathrm{L} \mathrm{NAA}$ and $0.5 \mathrm{mg} / \mathrm{L}$ kinase was used for plant regeneration. The result showed that during the initial stages of calli induction the anther cultures had varying rates of calli formation among genotypes, with the best frequency being observed for Dreami2/CaMsrB2-8-DH-1 with a calli frequency of $27.8 \%$. Different genotypes of rice cultured in regeneration media showed varying plantlet regeneration on media supplemented with different concentrations of maltose, with low concentrations $(0.04 \mathrm{~g} / \mathrm{L})$ leading to low frequency regeneration plantlet but high green plant production. Indeed, when Dreami2/CaMsrB2-8-DH-2 and Dreami2/CaMsrB2-8-DH-5 were cultivated under these conditions, $100 \%$ green plants were observed. Another genotype also showed a small rate of albino frequency in response to the lowest concentration of maltose, while increased maltose concentrations resulted in increased rates of albino plants. Overall, the results of this study should facilitate establishment of an efficient plant regeneration system from anther culture in rice.
\end{abstract}

Keywords: Anther Culture; Maltose; Oryza sativa; Plant Regeneration; Rice

\section{Introduction}

Anther culture has become the most popular method for production of homozygous lines for rice cultivars worldwide. Accordingly, rice anther culture has been intensively investigated. However, despite significant improvements, its practical application remains limited [1]. Nevertheless, anther culture has been widely integrated into rice breeding programs, allowing rapid production of homozygous double haploid lines from F1 hybrids and incorporation of new genes into breeding materials. The production of double haploids from anthers or isolated microspores culture in vitro is a rapid approach to homozygosity that shortens the time required for development of new rice cultivars through conventional methods, which require at least six generations. Haploids are also valuable for detection and repair of desirable recessive

${ }^{*}$ Corresponding author. traits introduced through mutation [2] or hybridization [3]. Double haploid techniques accelerate the breeding cycle and allow the production fertile line. A large number of rice varieties have been developed through anther culture and released for cultivation over several thousand hectares because the number of green plants obtained through anther culture did not meet the demands of practical exploitation [4]. Several factors influencing anther culture have been studied, including genotype of the explants $[5,6]$, growth condition of donor plants [7] and culture methods [8]. Although different protocols have been proposed to improve the efficiency of anther culture, green plant regeneration frequencies have remained rather low. To date, the application of anther culture to rice breeding has been hampered by low calli induction and plant regeneration frequency. Even good calli induction may result in predominant albino populations. A number of factors have been examined to determine the 
effects of various factors on calli regeneration frequency, such as genotypes, hormonal composition, culture methods, and carbohydrate sources $[9,10]$. The carbohydrate sources used for the induction and regeneration medium can have a profound effect on anther culture response. It has been known that some carbohydrate source, sucrose, is most commonly used for all types of tissue cultures. In comparison to sucrose, maltose has been found to be superior for green shoot regeneration in barley and effective as a carbon source for androgenesis [11]. In this study, we reported the effects of maltose as a carbohydrate source on calli induction and regenerated plant frequency.

\section{Materials and Methods}

\subsection{Preparation of Explants}

The experiment was conducted in the field using the following eight genotypes of rice, japonica type, Dreami2/CaMsrB2-8-DH-1, Dreami2/CaMsrB2-8-DH-2, Dreami2/CaMsrB2-8-DH-3, Dreami2/CaMsrB2-8-DH-4, Dreami2/CaMsrB2-23-DH-2,

Dreami2/CaMsrB2-23-DH-5,

Dreami2/CaMsrB2-23-DH-7, and Dreami2/CaMsrB223-DH-9. Pre germinated seeds from each genotype were sown under normal conditions during summer with complete nutrition.

\subsection{Anther Collection and Treatment}

Anthers were collected at the early flowering stage, when young panicles were still enclosed within the leaf sheath. Selection was based on a maximum distance between the auricle and the next subtending leaf of $5-10 \mathrm{~cm}$. These findings coincide with the mid-uninucleate stage, which is most responsive to anther culture. Panicles were collected from plants between 9:00 and 10:00 AM and then washed with tap water. After clipping the flag leaves, panicles were sprayed with $70 \%$ ethyl alcohol and then incubated in polyethylene bags in the dark at $8^{\circ} \mathrm{C}-12^{\circ} \mathrm{C}$ for 14 days.

\subsection{Calli Induction and Plant Regeneration}

The panicles of eight rice were carefully sprayed with $70 \%$ ethanol (v/v) and catch with pinset and burn on the fire just a few second, repeat this step 3 times. The panicles enclosed in the leaves were then opened, after which the disinfected capitula was plated on dry sterile filter papers. Flowerlets of the outer ring on the capitula were excised and torn open with two pairs of fine forceps, after which all five anthers were taken out from each flowerlet and immediately inoculated onto media for calli induction and incubation at $25^{\circ} \mathrm{C}$ in the dark for 30 days. About 40 anthers were inoculated on calli induction me- dium except those for comparison. Media for callies consisted of $\mathrm{N}_{6}$-medium, $2.0 \mathrm{mg} / \mathrm{L}$ NAA, $0.5 \mathrm{mg} / \mathrm{L}$ kinase and $4.0 \mathrm{~g} / \mathrm{L}$ maltose. The $\mathrm{pH}$ was adjusted to 5.8 with $1 \mathrm{~N}$ $\mathrm{HCl}$ or $1 \mathrm{~N} \mathrm{NaOH}$ before the addition of Gelrite, after which the media was autoclaved at $121^{\circ} \mathrm{C}$ for $20 \mathrm{~min}$.

Calli about $4-5 \mathrm{~mm}$ in size was transferred from the calli induction media onto regeneration media (approximately 10 per petri dish). Samples were then incubated under a 12-h light/12-h dark photoperiod with a light intensity of about $20 \mathrm{lmol} \cdot \mathrm{m}^{-2} \cdot \mathrm{s}^{-1}$ at $25^{\circ} \mathrm{C} \pm 1{ }^{\circ} \mathrm{C}$ for 30 days. Regeneration consisted of $\mathrm{N}_{6}-\mathrm{Y}_{1}$ medium (Duchefa) supplemented with various concentrations of maltose $(0.04 \mathrm{~g} / \mathrm{L}, 0.4 \mathrm{~g} / \mathrm{L}$ and $4.0 \mathrm{~g} / \mathrm{L}), 2 \mathrm{mg} / \mathrm{L}$ NAA, and 0.5 $\mathrm{mg} / \mathrm{L}$ Kinase. The $\mathrm{pH}$ was adjusted to 5.8 with $1 \mathrm{~N} \mathrm{HCl}$ or $1 \mathrm{~N} \mathrm{NaOH}$ before the addition of gelrite and the media was then autoclaved at $121^{\circ} \mathrm{C}$ for $20 \mathrm{~min}$.

The appearance and proliferation of calli were observed and recorded every five days. In media induction calli and after 30 days, the regenerated calli in regeneration media was also observed every week, 8 dishes were randomly chosen for analysis data. The total number of calli formed and plantlet regeneration frequency (albino and green) were recorded for analysis.

\section{Results}

\subsection{Calli Induction from Anther Culture}

Eight rice variety were tested for assessment of anther calli induced response, anther from each genotype was cultured separately on same $\mathrm{N}_{6}$ induction media. Of these different genotype, total number of survived callidan brown calli (death calli) were observed (Figure 1). The result showed varian number of inoculated anther from different genotype resulted different total number of calli can be induced in this media. Among the eight responding genotype rice, almost all anther from ech genotype can be induced to calli in this media, but the some of calli showed not progress to grow up and marked with brown color (Figure 1). The comparison total number brown calli and white calli on different was showed in Figure 2(Y). In the response genotype on white calli, Dreami 2/CaMsrB2-8-DH-7 showed best response in $\mathrm{N}_{6}$ induction medium, where the frequency of calli induction was $27.9 \%$, followed by Dreami2/CaMsrB2-8-DH-1 occurring ata frequency of $26.8 \%$. The lowest frequency of white calli was $9.9 \%$ and $3.5 \%$ for Dreami2/CaMsrB223-DH-5 at frequency and Dreami2/CaMsrB2-23-DH-2 in Figure 2(Z).

\subsection{Plant Regeneration of Calli}

In this study, we used regeneration media containing different concentrations of maltose. After 4 - 6 weeks, the calli diameter was about $1 \mathrm{~cm}$, and embryogenic callies 


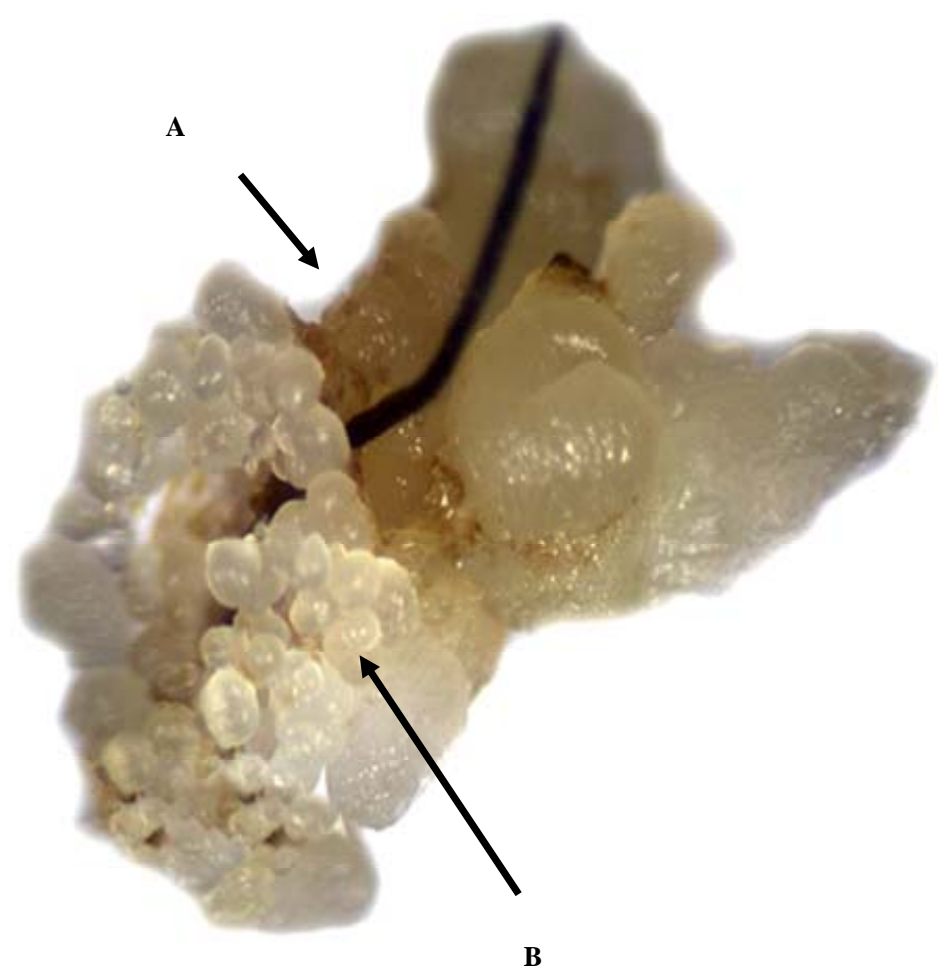

Figure 1. Calli formation at four weeks from anther culture during medium induction. A: Brown calli formation (None-embryogenic), B: White calli formation (Embryogenic).
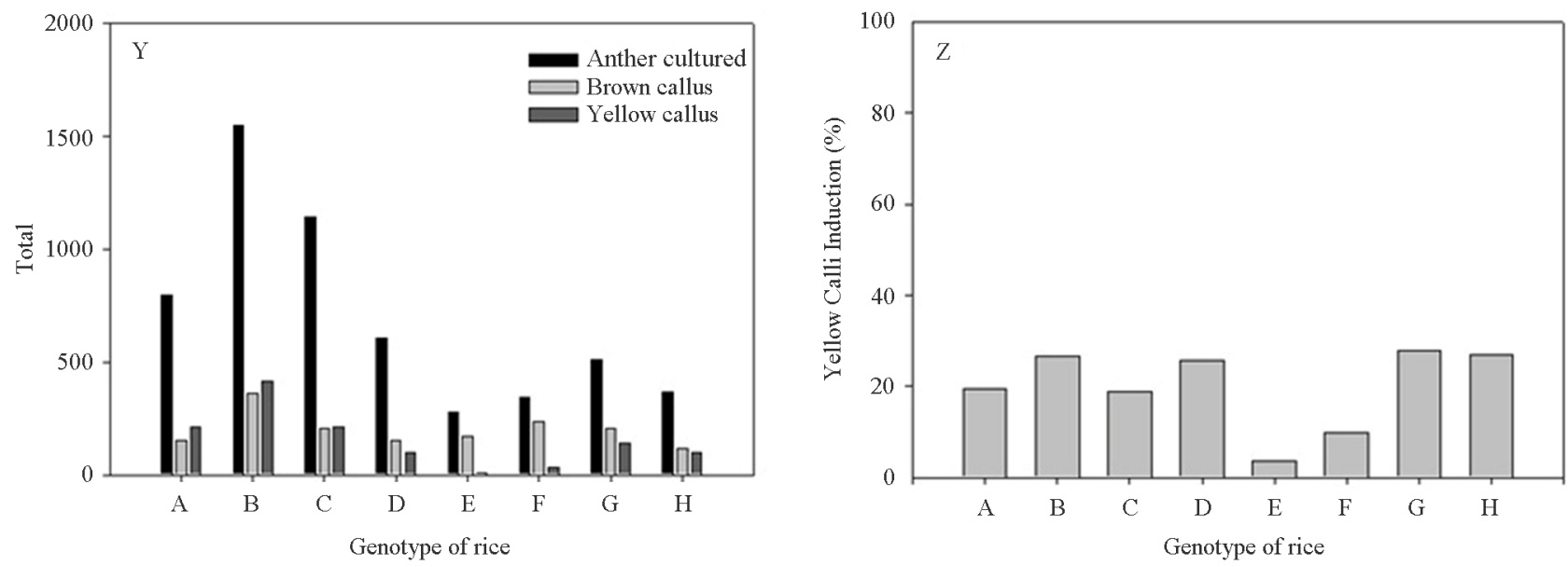

Figure 2. (Y) Total number of anthers inoculated and total number of brown callies induced by different genotype rice; (Z) Percent of white calli induction by different genotype of rice. A: Dreami2/CaMsrB2-8-DH- 1, B: Dreami2/CaMsrB2-8-DH-2, C: Dreami2/CaMsrB2-8-DH-3, D: Dreami2/CaMsrB2-8-DH-4, E: Dreami2/CaMsrB2-23-DH-2, F: Dreami2/CaMsrB2-23-DH-5, G: Dreami2/CaMsrB2-23-DH-7, H: Dreami2/CaMsrB2-23-DH-9.

were generated upon transfer into regeneration media. Approximately 4 weeks later, green spots appeared on the surface of callies grown in regeneration media (Figure 3). The number of plantlets was then used as a parameter to determine the effects of different maltose concentrations on regeneration of plantlets from callies. Our data showed that different maltose concentrations can influence the total number of plantlets and the albino effect on plantlets. The different concentrations of maltose had different effects on plant regeneration among rice genotypes. On the concentration maltose $0.04 \mathrm{~g} / \mathrm{L}$ and $0.4 \mathrm{~g} / \mathrm{L}$ has no major impact on the regeneration plant, all genotype rice can generated in this media. The concentration maltose $4.0 \mathrm{~g} / \mathrm{L}$ had indicated major impact on the regeneration plantlet. This concentration was great effect on the some of genotype rice; however, in the contrast, 


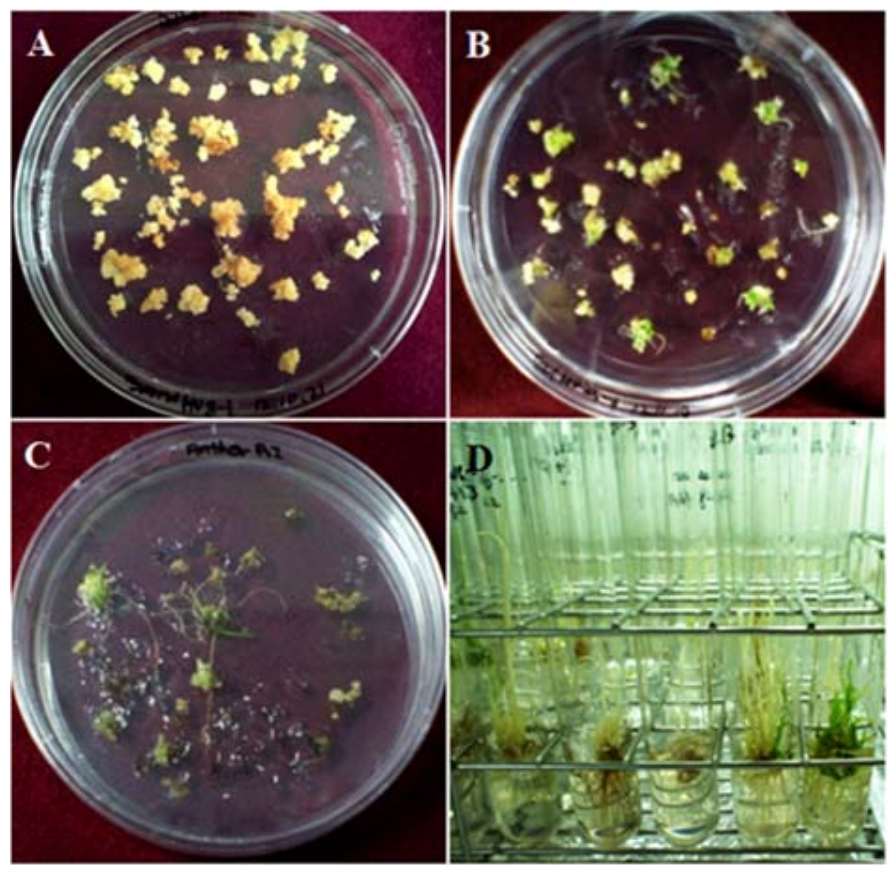

Figure 3. Plant regeneration from anther derived callies. (A) Calli induction from anther culture at 20 days; (B) Embryogenic callies with green spots after culture in regeneration medium; (C) Shoot regeneration from embryogenic callies approximately 28 days after culture on regeneration medium; (D) Plantlets from regenerated anthers, some of which showed green color and others that showed no color (albino).

this effect was not great in Dreami2/CaMsrB2-23-DH-5 and Dreami2/CaMsrB2-23-DH-7, all callies could not be generated in this concentration (Table 1). Moreover, maltose effect on regeneration planlet was also determined by genotype of rice.

We also observed the ratio of albino plants to green plant in response to different maltose concentrations (Table 2). The results showed that the lowest albino plant frequency occurred with the lowest concentration of maltose $0.04 \mathrm{~g} / \mathrm{L}$. Additionally, Dreami2/CaMsrB2-8-DH-2 and Dreami2/CaMsrB2-8-DH-5 produced almost no albino plants in this media, this maltose concentration indicating that it could be used for plantlet generation. In the concentration maltose $0.4 \mathrm{~g} / \mathrm{L}$, The frequency of the total albino plants was great in some genotypes of rice Dreami2/CaMsrB2-23-DH-1 and

Dreami2/CaMsrB2-23-DH-2. And the concentration 4.0 $\mathrm{g} / \mathrm{L}$, showed the frequency of albino plants was about two folds greater than that of green plant in all genotype of rice. The increased of maltose concentration have affected on the total number of albino plantlet.

\section{Discussion}

The results showed that maltose as a carbon source used for rice anther culture can have an effect on genetic response. Maltose induced callies and green shoot regeneration in a variety of rice genotypes. Maltose could be used to regenerate plantlets from callies, and the lowest concentration of maltose was shown to be the best treatment to obtain green plants. Increased maltose concentration was associated with increased albino plants, but the frequency of albinos varied by genotype. Dreami2/ CaMsrB2-8-DH-1, Dreami2/CaMsrB2-8-DH-2, and Dreami2/CaMsrB2-8-DH-3 could all be regenerated on all media investigated at different maltose concentrations. The addition of maltose to the plant regeneration medium appeared to have a beneficial effect beyond that seen with maltose in the medium. However, maltose does not appear to be essential for green shoots as they are also formed without any carbohydrate source. The effects of maltose and alternative carbohydrates have been documented in several tissue culture systems, but the reason for their superiority to sucrose is not known. Other researchers have indicated that maltose improves the osmotic stability of culture medium compared to sucrose [11]. It has also been reported that maltose stimulates embryogenesis at low concentrations [12], which is analogous with the finding that increased maltose concentrations resulted in the generation of higher numbers of plantlets in the present study. Albino plants, which are frequently regenerated from pollen-derived callies, are often limiting factors in rice anther culture [13]. Additionally, the albino plant generation is specific to anther culture [14] and only a few albino plants are generated from somatic cells [15]. It is well known that the 
Table 1. Total plantlet regeneration per 100 anthers from different genotypes to various maltose concentrations.

\begin{tabular}{cccc}
\hline \multirow{2}{*}{ Genotypes of rice } & \multicolumn{2}{c}{ Total number of plantletsregenerated per 100 anthers } \\
\cline { 2 - 4 } & $0.04 \mathrm{~g} / \mathrm{L}$ Maltose & $0.4 \mathrm{~g} / \mathrm{L}$ Maltose & $4 \mathrm{~g} / \mathrm{L}$ Maltose \\
\hline Dreami2/CaMsrB2-8-DH-1 & $34 \pm 2.5^{*}$ & $30 \pm 2.1$ & $66 \pm 2.5$ \\
Dreami2/CaMsrB2-8 DH-2 & $27 \pm 2.2$ & $19 \pm 2.5$ & $97 \pm 5.1$ \\
Dreami2/CaMsrB2-8-DH-3 & $18 \pm 1.4$ & $37 \pm 4.9$ & $64 \pm 1.7$ \\
Dreami2/CaMsrB2-23-DH-5 & $7 \pm 1.1$ & $8 \pm 1.7$ & $0 \pm 0.0$ \\
Dreami2/CaMsrB2-23-DH-7 & $25 \pm 3.1$ & $14 \pm 1.3$ & $0 \pm 0.0$ \\
\hline
\end{tabular}

${ }^{*} \mathrm{Mean} \pm \mathrm{SD}$.

Table 2. Plantlet regeneration ratio (green and albino) from different genotypes of rice to various maltose concentration.

\begin{tabular}{|c|c|c|c|c|c|c|}
\hline \multirow{3}{*}{ Genotype of rice } & \multicolumn{6}{|c|}{ Plantlet regeneration ratio frequency (\%) } \\
\hline & \multicolumn{2}{|c|}{$0.04 \mathrm{~g} / \mathrm{L}$ Maltose } & \multicolumn{2}{|c|}{$0.4 \mathrm{~g} / \mathrm{L}$ Maltose } & \multicolumn{2}{|c|}{$4 \mathrm{~g} / \mathrm{L}$ Maltose } \\
\hline & Normal & Albino & Normal & Albino & Normal & Albino \\
\hline Dreami2/CaMsrB2-8-DH-1 & $88.5 \pm 1.4$ & $11.4 \pm 1.4$ & $43.3 \pm 0.1$ & $56.6 \pm 1.1$ & $30.3 \pm 3.5$ & $69.6 \pm 2.1$ \\
\hline Dreami2/CaMsrB2-8 DH-2 & $100.0 \pm 3.1$ & $0.0 \pm 0.0$ & $31.5 \pm 3.1$ & $68.4 \pm 1.5$ & $36.0 \pm 1.4$ & $64.0 \pm 2.5$ \\
\hline Dreami2/CaMsrB2-8-DH-3 & $94.4 \pm 3.5$ & $5.4 \pm 3.1$ & $64.8 \pm 3.5$ & $35.1 \pm 3.1$ & $34.3 \pm 4.5$ & $65.6 \pm 5.1$ \\
\hline Dreami2/CaMsrB2-23-DH-5 & $100.0 \pm 4.6$ & $0.0 \pm 0.0$ & $62.5 \pm 13.0$ & $37.5 \pm 2.5$ & $0.0 \pm 0.0$ & $0.0 \pm 0.0$ \\
\hline Dreami2/CaMsrB2-23-DH-7 & $84.0 \pm 0.4$ & $16.0 \pm 3.5$ & $85.7 \pm 6.6$ & $14.2 \pm 2.2$ & $0.0 \pm 0.0$ & $0.0 \pm 0.0$ \\
\hline Average & $93.4 \pm 2.6$ & $6.6 \pm 1.6$ & $57.6 \pm 5.3$ & $42.4 \pm 2.1$ & $33.6 \pm 1.9$ & $66.4 \pm 1.9$ \\
\hline
\end{tabular}

frequency of albino plants during anther cultures in rice is controlled by nuclear genes [16]. The results of the present study indicated a correlation between the maltose concentration in media and frequency of albino plants. Specifically, application of the lowest concentration of maltose minimized the frequency of albino plants from anthers, but they still occurred. Overall, the results of this study can be used as a reference for development of additional anther culture techniques.

\section{Acknowledgements}

This work was supported by a grant from the Next-Generation BioGreen 21 Program (No. PJ0080912013), Rural Development Administration, Republic of Korea.

\section{REFERENCES}

[1] S. K. Raina, "Doubled Haploid Breeding in Cereals," In: J. Janick, Ed., Plant Breeding Reviews, Vol. 15, John Wiley \& Sons, Inc., Canada, 1997, pp. 141-186.

[2] Q. F. Chen, C. L. Wang, Y. M. Lu, M. Shen, R. Afza, M. V. Duren and H. Brunner, "Anther Culture in Connection with Induced Mutations for Rice Improvement," Euphytica, Vol. 120, No. 3, 2001, pp. 401-408. http://dx.doi.org/10.1023/A:1017518702176

[3] T. He, Y. Yang, S. B. Tu, M. Q. Yu and X. F. Li, "Selection of Interspecific Hybrids for Anther Culture of Indica Rice," Plan Cell Tissue and Organ Culture, Vol. 86, No. 2, 2006, pp. 271-277. http://dx.doi.org./10.1007/s11240-006-9117-z

[4] D. Y. Zhu, X. H. Ding, J. H. Ying, N. Q. Jie and H. L. Xiong, "Genetic Studies on Anther Culture Ability of Indica Rice," In: H. Hu and L. H. Wang (Eds.), Plant Cellengineering and Crop Improvement, Beijing Industrial University Press, Beijing, 1990, pp. 38-43.

[5] J. H. Shen, M. F. Li, Y. Q. Chen and Z. H. Zhang, "Breeding by Anther Culture in Rice Varieties Improvements," Scientia Agricultura Sinica, Vol. 2, No. 2, 1982, pp. 15-19.

[6] M. F. Li, "Anther Culture Breeding of Rice," In: C. J. Yan (Ed.), Tissue Culture of Field crops, Shanghai Scientific and Technical Publishers, Shanghai, 1991, pp. 135152.

[7] Y. Chen, "In Vitro Development of Plant from Microspores of Rice," In: H. Hu and Y. Chen (Eds.), Plant Somatic Genetics and Crop Improvement, Beijing University Press, Beijing, 1988, pp. 27-67.

[8] R. D. Qu and Y. Chen, "A Preliminary Research on the Function of Enhancement of Calli Induction Frequency by Cold Pretreatment in Rice Anther Culture," Acta Phytophysiologica Sinica, Vol. 9, No. 4, 1983, pp. 375-381.

[9] J. Asad, Q. M. Hassan, T. Fatima and T. Hasnain, "Tissue Culture Response of Local Varieties of Rice (Oryza sativa L.) of NWFP," Journal of Biological Sciences, Vol. 1, No. 5, 2001, pp. 387-390. http://dx.doi.org/10.3923/jbs.2001.387.390

[10] J. M. She, B. L. Zhang and W. C. Ni, "Factors Affecting Plant Regeneration from Calli of Mature Embryo of 'Yangdao 6',' Jiangsu Journal of Agricultural Sciences, 
Vol. 18, No. 4, 2002, pp. 199-202.

[11] U. Kuhlmann and B. Foroughi-Wehr, "Production of Double d Haploid Line in Frequencies Sufficient of Barley Breeding Program," Plant Cell Reports, Vol. 8, No. 2, 1989, pp. 78-81. http://dx.doi.org./10.1007/BF00716843

[12] S. D. Strickland, J. W. Nichol, C. M. McCall and D. A. Stuart, "Effect of Carbohydrate Source on Alfalfa Somatic Embryogenesis," Plant Science, Vol. 48, No. 2, 1987, pp. 113-121.

http://dx.doi.org/10.1016/0168-9452(87)90138-5

[13] M. Yamagishi, "Heterogeneous Plastid Genomes in Anther Culture-Derived Albinorice Plants," Euphytica, Vol. 123, No. 1, 2002, pp. 67-74.

http://dx.doi.org/10.1023/A:1014493316433
[14] H. Niizeki and K. Oono, "Induction of Haploid Rice Plant from Anther Culture," Proceedings of the Japan Academy, Vol. 44, No. 6, 1968, pp. 554-557.

[15] M. Tsukahara, T. Hirosawa and H. Murayama, "Effect of Culture Methods on the Regeneration of Albino Rice (Oryza sativa L.) Plantlets," Plant Cell Reports, Vol. 15, No. 8, 1996, pp. 597-600. http://dx.doi.org/10.1007/BF00232460

[16] C. A. Quimio and F. J. Zapata, "Diallel Analysis of Calli Induction and Green-Plant Regeneration in Rice Anther Culture," Crop Science, Vol. 30, No. 1, 1990, pp. 188192.

http://dx.doi.org/10.2135/cropsci1990.0011183X0030000 $\underline{10041 x}$ 